Review

\title{
Toxins and drug discovery
}

\author{
Alan L. Harvey ${ }^{\mathrm{a}, \mathrm{b}}$, * \\ a Research and Innovation Support, Dublin City University, Dublin 9, Ireland \\ ${ }^{\mathrm{b}}$ Strathclyde Institute for Pharmacy and Biomedical Sciences, University of Strathclyde, Glasgow G4 ORE, UK
}

\section{A R T I C L E I N F O}

\section{Article history:}

Received 20 August 2014

Accepted 15 October 2014

Available online 29 October 2014

\section{Keywords:}

Drug discovery

Drug development

Venoms to drugs

Snake venoms

Conus venoms

Phenotypic screening

\begin{abstract}
A B S T R A C T
Components from venoms have stimulated many drug discovery projects, with some notable successes. These are briefly reviewed, from captopril to ziconotide. However, there have been many more disappointments on the road from toxin discovery to approval of a new medicine. Drug discovery and development is an inherently risky business, and the main causes of failure during development programmes are outlined in order to highlight steps that might be taken to increase the chances of success with toxin-based drug discovery. These include having a clear focus on unmet therapeutic needs, concentrating on targets that are well-validated in terms of their relevance to the disease in question, making use of phenotypic screening rather than molecular-based assays, and working with development partners with the resources required for the long and expensive development process.
\end{abstract}

(C) 2014 The Author. Published by Elsevier Ltd. This is an open access article under the CC BY-NC-ND license (http://creativecommons.org/licenses/by-nc-nd/3.0/).

\section{Introduction}

While venoms featured in several systems of traditional healing, the modern translation of toxins into medicines began in the 1940s with the introduction of tubocurarine into anaesthetic practice as a selectively acting muscle relaxant (Bowman, 2006). Tubocurarine is one of the key active ingredients in curare, the South American arrow poison. By binding to nicotinic acetylcholine receptors at the neuromuscular junction, tubocurarine blocks the transmission of excitatory signals from motor nerves to skeletal muscles, causing muscle paralysis. Use of tubocurarine allowed patients undergoing major surgery to be paralysed without using dangerously high doses of general anaesthetics. Although this revolutionised anaesthetic practice, the search soon began for new agents that lacked the cardiovascular side effects of tubocurarine. Since tubocurarine was known to have a relatively rigid core structure carrying two functional groups, most discovery work focused on synthetic compounds with curarimimetic actions: the toxin provided the template for drug design. Relatively little work involved explorations of other toxins that could cause paralysis. However, the most successful of the new muscle relaxants, atracurium, did draw on naturally-occurring curare-like alkaloids (Stenlake et al., 1983). Two relatively innocuous moieties were chemically linked to form the active molecule. The chemical bridge was designed to break down

\footnotetext{
* Strathclyde Institute for Pharmacy and Biomedical Sciences, University of Strathclyde, Glasgow G4 ORE, UK.

E-mail addresses: alan.harvey@dcu.ie, a.l.harvey@strath.ac.uk.
}

rapidly in plasma in order to provide elimination that was not dependent on liver or kidney function and to give a short-acting agent to facilitate the control of the duration of the paralysis. By chance, atracurium lacks the cardiovascular side effects of other muscle relaxants (blockade of nicotinic receptors in sympathetic ganglia that leads to a pronounced fall in blood pressure, and/or block of muscarinic cholinoceptors innervated by the cardiac vagus that could trigger arrhythmias). Atracurium was introduced in 1983, followed by cis-atracurium (a defined isomer) in 1995.

Other sources of arrow poisons, notably extracts of frog skin, were studied in the 1970s and '80s. While many compounds with interesting pharmacological actions were discovered (Daly, 1982; Philippe and Angenot, 2005), none has led to a successful medicine. However, the discovery of epibatidine and its analgesic effects indicated that neuronal nicotinic receptors could be a possible therapeutic target. Structurally related compounds were tested by the Abbott company, including tebanicline (ABT-594) that reached phase II clinical trials before being dropped because of its side effects (Arneric et al., 2007).

There was, however, a notable success from research on snake venoms, namely the development of captopril, the inhibitor of angiotensin converting enzyme (ACE). This work was based on small peptides from the venom of the South American snake Bothrops jararaca that were known to potentiate the action of bradykinin (for reviews, see Opie and Kowolik, 1995; Camargo et al., 2012). Although bradykinin potentiating peptides are not toxins in the sense of having a potentially lethal action, they do come from a venom of a snake that is dangerous to humans. Work in Brazil and London explored the concept that bradykinin potentiating peptides 
could inhibit the enzyme that was responsible for the production of vasoactive angiotensin (Smith and Vane, 2003). The hypothesis was that systemic blood pressure would be lowered by blocking angiotensin converting enzyme. This was demonstrated experimentally and in humans with the synthetic bradykinin potentiating peptide teprotide in 1971. However, teprotide had to be injected, an obvious disadvantage for treating patients with high blood pressure. Considerable effort led to the orally acting ACE inhibitor captopril, which was introduced in 1981 (Cushman et al., 1977). Since then, many follow-up compounds have been introduced.

\section{More recent successes}

Captopril's success is generally credited as triggering the recognition that venoms could be the source of new medicines (Harvey, 1992; Lewis and Garcia, 2003; Fox and Serrano, 2007; Shaw, 2009; King, 2011; Koh and Kini, 2012; Takacs and Nathan, 2014), but further successes have been rare. While snake venoms were recognised as the source of enzymes with specific actions on many of the components in the blood clotting cascade (Kornalík, 1991), there were no further developments of non-enzymatic compounds until the almost simultaneous introduction of eptifibatide and tirofiban in 1998. These act on GPIIb/IIIa integrin receptors on blood platelets to prevent platelet aggregation and thrombus formation. Clinically, they are used in patients with acute coronary syndrome and in high-risk patients undergoing coronary interventions. Both compounds owe their existence to research on snake venoms. Eptifibatide is a synthetic cyclic heptapeptide that mimics the action of a much larger peptide ( 73 amino acids) found in the venom of the southeastern pigmy rattlesnake Sistrurus miliarius barbouri. Tirofiban is not a peptide but it is based on a 49residue polypeptide from a snake venom, echistatin from the saw-scaled viper Echis carinatus. Both compounds were designed to mimic the RGD sequence that is the recognition motif for binding to GPIIb/IIIa integrin receptors (Hashemzadeh et al., 2008).

More recently, venoms from sources other than snakes have attracted attention. Venoms from marine cone snails (Conus) have been proposed as promising sources of new drug leads (e.g., Lewis and Garcia, 2003; Twede et al., 2009; Essack et al., 2012; Vetter and Lewis, 2012) because they contain a rich variety of small peptides with diverse pharmacological actions. Ziconotide, the synthetic version of the venom peptide MVIIA from Conus magus, was approved by the FDA in 2004 for treating patients with intractable pain. The compound selectively blocks N-type calcium ion channels $\left(\mathrm{Ca}_{\mathrm{v}} 2.2\right)$; when administered intrathecally, it can reduce pain transmission in the spinal cord (Pope and Deer, 2013).

Sometimes included as successes in drug discovery and development from venom components are compounds inspired by molecules that are not exactly toxins and from sources that are not exactly venoms. Examples include variants of hirudin, the anticoagulant thrombin antagonist from the saliva of the medicinal leech, Hirudo medicinalis and exenatide, the GLP-1 agonist peptide from the saliva of the Gila monster lizard, Heloderma suspectum that is in use as an anti-diabetic agent (King, 2011; Takacs and Nathan, 2014).

Arguably, the biggest successes in translating toxins to products in recent years have been the developments from the microbial botulinum toxins. Both botulinum toxins $\mathrm{A}$ and $\mathrm{B}$ have been approved for clinical use to treat patients with a variety of conditions caused by over-activity of neurones. By restricting the toxins' actions by localised injections and through their highly selective uptake into particular nerves, botulinum toxins have been used successfully in, e.g., strabismus, blepharospasm, dystonias, hyperhidrosis and migraine (Abrams and Hallett, 2013; Matak and Lacković, 2014). Of course, many sales are derived from the use of botulinum preparations for cosmetic purposes, but further therapeutic applications have been proposed (Dolly et al., 2011). In recent developments, a topical formulation of botulinum toxin $\mathrm{A}$ (RT001) was efficacious in a double-blind trial to treat facial wrinkles (Glogau et al., 2012) and another topical formulation (ANT-1207) is currently in phase II clinical trials (http:// clinicaltrials.gov/show/NCT01293552; http://clinicaltrials.gov/ show/NCT01358695).

\section{Trials and tribulations}

Earlier reviews on the potential of toxin-related compounds have lists of products in clinical trials (King, 2011; Takacs and Nathan, 2014). Unfortunately, several of these products have since been dropped, illustrating how difficult it can be to go from promising effects in animal studies to beneficial and side-effectfree actions in humans.

Following the example of the conopeptide ziconotide, other Conus peptides have been pursued. A calcium ion channel blocker from Conus catus, $\omega$-conotoxin CVID (variously named AM336, CNSB004 and leconotide) failed in clinical trials because of side effects encountered; these trials involved intrathecal administration, but the peptide was to be tried again using intravenous administration (Kolosov et al., 2010). However, the company responsible for the development, Relevare Pharmaceuticals, is in liquidation (https://insolvencynotices.asic.gov.au/browsesearchnotices/notice-details/Relevare-Pharmaceuticals-Ltd-142658259) The $\alpha$-conotoxin Vc1.1 (ACV1) from Conus victoriae failed because of lack of efficacy: while this compound was identified as an antagonist of subtypes of neuronal nicotinic cholinoceptors, it was subsequently shown to have analgesic potential by acting through a rather different mechanism, that of activating GABA-B receptors and causing a decrease in calcium ion currents in nociceptive neurones (Adams and Berecki, 2013). Xen2174, the synthetic analogue of the $\chi$-conopeptide Mr1A from Conus marmoreus, inhibits noradrenaline reuptake in neurones and has profound analgesic activity in animal studies (Lewis, 2012); however, it was also found to have dose-limiting toxicity in humans despite early promise in Phase I trials (Groeneveld, 2013).

Chlorotoxin from the venom of the scorpion Leiurus quinquestriatus was first identified as a blocker of some chloride ion channels and then found to inhibit matrix metalloproteinases (Deshane et al., 2003). It showed promise as a means to identify glioma tumour cells and, potentially, as a way to localise anti-cancer agents to such tumour cells (Wu et al., 2010). However, clinical trials with chlorotoxin and conjugates with ${ }^{131} \mathrm{I}$ appear to have been suspended (http://clinicaltrials.gov/ct2/show/NCT00733798) following a takeover of the development company.

Some compounds featured in earlier review articles do still appear to be under active investigation. A snake venom natriuretic peptide DNP (from green mamba Dendroaspis angusticeps) has been fused with human $C$-type natriuretic peptide to provide a molecule, CD-NP or cenderitide, that activates both A and B forms of the natriuretic peptide receptor, with the expectation that this would give both improved efficacy and a longer duration of action in patients with heart failure (McKie et al., 2010; Vink et al., 2012). A clinical trial assessing the pharmacokinetics, pharmacodynamics, safety and tolerability of subcutaneous administration of cenderitide in patients with chronic heart failure has been completed and a pilot study for the preservation of left ventricular function in patients after myocardial infarction is underway (https://clinicaltrials. gov/ct2/show/NCT02071602).

A synthetic peptide ShK-186 related to the potassium ion channel blocker ShK from the sea anemone Stichodactyla helianthus (Chi et al., 2012) is also in early-stage clinical trials (company website: http://www.kinetabio.com/autoimmune.html). The 
modified peptide is more specific than the native peptide for the Kv1.3 subtype of voltage-activated potassium ion channels (Beeton et al., 2011). These channels are important for the activation of Tcells in autoimmune diseases. Blocking the channels by ShK-186 may be efficacious in multiple sclerosis and other autoimmune diseases.

Most of the agents described above reached clinical trials because of their highly selective mechanism of action, e.g. ShK-186 blocks Kv1.3 subtypes of potassium ion channels but not any of the closely related voltage-activated potassium ion channels. It is, therefore, perhaps surprising that tetrodotoxin, which blocks most subtypes of sodium ion channels, is also in clinical trials. Most of the clinical work has been in Canada with patients suffering from severe cancer-related pain (Hagen et al., 2007, 2008, 2011). Results show some promise, with some patients noting improvements in symptoms, but more extensive testing may prove to be more demanding.

The US biotechnology company ReceptoPharm reports that it has completed phase I clinical trials with detoxified versions of $\alpha$ cobrotoxin (isolated from the venom of the cobra Naja nivea) and $\alpha$ cobratoxin (from the venom of Naja kaouthia) (company website: http://www.receptopharm.com/drug_development/pipeline.php). In vitro studies showed that modified toxin or detoxified cobra venoms stimulated the production of cytokines, including interferon- $\gamma$, by human T-cells (US Patent, 2010). The company is intending to conduct further clinical trials in multiple sclerosis, motor neurone disease, adrenomyeloneuropathy and viral infections.

\section{Still to come?}

As mentioned earlier, venoms from Conus marine snails are enthusiastically regarded as sources of drug leads. A bioinformatics approach led the authors to highlight "98 recently identified conotoxins with therapeutic potential" (Essack et al., 2012). Earlier discussions focused on neuro- and cardio-protective conopeptides, including conantokins that block NMDA receptors and several potassium ion channel blockers (Twede et al., 2009). Their development was being undertaken by the US biotechnology company Cognetix that has subsequently closed (King, 2011). Other conopeptides targeting sodium ion channels and various receptors (for acetylcholine, neurotensin, noradrenaline and 5hydroxytryptamine) have been highlighted by Vetter and Lewis (2012). Little is known about their progress towards clinical development. A $\mu$-conotoxin (XEP-018) from Conus consors venom was reported to be moving into preclinical development on account of its particularly long duration of action (Stöcklin, 2012) but its current status is unknown.

While Conus venoms have attracted most attention, venoms from other sources are also being explored. Various scorpion, spider, bee and wasp venoms have provided toxins that have been tested experimentally for effects that could relate to therapeutic benefit (Klint et al., 2012; Mortari and Cunha, 2013). There are many reports of positive results on animal models of pain and epilepsy, but there have not yet been clinical developments. The French biotechnology company Theralpha reported intentions to develop a spider toxin PcTx1 as a potential analgesic because of its specific effects on ASIC1a ion channels, one of the acid sensing channels; however, Theralpha appears to have gone out of operation.

Snake venoms also continue to be explored for molecules with therapeutic potential (e.g. King, 2011; Earl et al., 2012; Koh and Kini, 2012; Vink et al., 2012). Several compounds of interest come from venoms of Australian snakes, and their potential applications include preventing bleeding (textilin-1, Q8008), reducing blood loss and haemorrhage (pseudotarin C components, Haempatch and CoVase), and reversing congestive heart failure (natriuretic peptides from Taipan venom). These seem to have had a troubled commercial history. Textilin-1, Haempatch and CoVase were being developed by the Australian company QRx Pharma, and were the basis of a joint venture agreement between the subsidiary company Venomics and a Chinese company Liaoning Nuokang Medicines Company Ltd in 2009: no development has been reported recently. The natriuretic peptides were to be developed by another Australian company ElaCor, but this company was delisted in 2010 (Commonwealth of Australia Gazette, 2010). An earlier development that was based on another component from Taipan venom, Oxynor, was reported to be in clinical development for wound healing (Lipps, 2004), but the company responsible for this, Ophidia Products, no longer seems to be operational.

Vicrostatin, a chimeric protein based on the disintegrins echistatin and contortrostatin, inhibits angiogenesis and is being tested in animal models as the basis of an anti-cancer agent (Minea et al., 2012). Development will take place through the start-up company Applied Integrin Sciences Inc.

Snake venoms have also provided components that have analgesic actions in animal models. For example, the $\alpha$-neurotoxin hannalgesin from venom of the king cobra Ophiophagus hannah $(\mathrm{Pu}$ et al., 1995) was the basis of a small peptide named prohanin (US Patent, 2003). Despite being based on the sequence of an $\alpha$ neurotoxin and, hence, of a nicotinic cholinoceptor antagonist, prohanin does not paralyse skeletal muscles, but appears to act as an analgesic via involvement of nitric oxide synthase and to be well absorbed sublingually (US Patent, 2003; US Patent Application, 2012). Prohanin was reported to be in preclinical development (Koh and Kini, 2012; US Patent Application, 2012). Unfortunately, the development was to be carried out by the company Theralpha that has closed (RM Kini, personal communication, 2014).

Venom of the South American rattlesnake Crotalus durissus terrificus also has analgesic actions in experimental animals, even on oral administration (Giorgi et al., 1993). A 14-residue peptide with one disulphide bridge is involved. This peptide, named crotalphine, has been studied extensively (e.g. Konno et al., 2008; Zambelli et al., 2014). Some of its actions are mediated through $\kappa$-opioid receptors, with an involvement of pathways including nitric oxide (Gutierrez et al., 2012) and cannabinoids (Machado et al., 2014). Crotalphine is being treated as a possible development candidate (US Patent Application, 2009) and is currently in the pre-clinical phase with the Brazilian company Biolab Farmaceutica.

More recently, peptides with analgesic actions were identified in the venom of the black mamba snake, Dendroaspis polylepis polylepis (Diochot et al., 2012). The active compounds are novel members of the three-finger toxin family, although they are not themselves toxic in mice. The compounds, named mambalgins, block acid-sensing ion channels (ASICs) in peripheral and central neurons, and are active in a variety of pain models (Diochot et al., 2012; Baron et al., 2013). The mambalgins were to be developed by Theralpha.

Another potential mechanism for an analgesic effect is to block the $\mathrm{Na}_{\mathrm{v}} 1.7$ subtype of sodium ion channels, and a highly selective blocker of this channel type has been found in the venom of the centipede Scolopendra subspinipes mutilans (Yang et al., 2013). The active component is a 46-residue peptide named $\mu$-SLPTX-Ssm6a, and it is hoped that this may be a lead to a novel class of analgesics.

Outside of medicines development, a spider-derived peptide directed at ion channels has been approved by the Environmental Protection Agency in the USA as a potential insecticide (see company website http://www.vestaron.com/epa-approval/). 


\section{Where do drugs come from?}

In the last 30 years, the FDA has approved 1355 new drugs (Newman and Cragg, 2012) and 1453 in all years up to 2013 (Kinch et al., 2014). From the discussions above, it is clear that very few of these are toxins or are derived or inspired by toxins or venom components: atracurium, captopril, eptifibatide, tirofiban, ziconotide and several botulinum toxin products. Despite that, publications from toxinologists continue to include optimistic statements about the benefits of toxins as starting points for drug discovery and development. Also, it is sometimes stated that 'biologics' as opposed to conventional small molecules appear to be gaining favour with development companies and with regulatory authorities. The large-molecule NMEs (generally proteins and peptides) have had a higher success rate than small-molecule NMEs: $13.2 \%$ compared with 7.6\% (Hay et al., 2014). However, the large molecules include growth factors and other substitutes for endogenous proteins. These would be expected to succeed in clinical development.

In overall terms, while the numbers of approved small molecule drugs ('New Molecular Entities') appear more or less stable over the last 10 years, the number of therapeutic biologics (as opposed to others such as vaccines and protein-based diagnostic agents) is not on a consistently upward trend between 2004 and 2013 (Fig. 1). Moreover, the number of biotechnology companies involved in FDA-approved medicines has been decreasing in recent years (Kinch, 2014a,b).

It has also been pointed out that toxin-related peptides are frequently very stable (because of their intramolecular disulphide bridges), that large-scale synthesis of peptides is becoming feasible, and that drug delivery systems are being developed for peptides (King, 2011; Vetter and Lewis, 2012). These advantages have yet to be seen in clinical development: a review of biologics in clinical trial or under examination by the FDA identified 907 products (PhRMA, 2013). Approximately half were vaccines and other products that would not be categorised as 'therapeutic biologics'. Of the remainder, the vast majority were monoclonal antibodies; there were very few peptides or proteins. The only toxin-related products were seven involving different forms of botulinum toxin $A$.

While the numbers of therapeutic biologics are not particularly increasing in recent years, a more serious concern is the relatively low number of new medicines in total (Fig. 1). There were 39 approved by the FDA in 2012, but most years have been closer to the annual average for 2004 to 2013 of 26 . This seems a disappointing return on the annual investment of more than $\$ 50$ billion in worldwide pharmaceutical research and development.

What factors contribute to the success or failure of drug discovery and development projects, and is it possible for toxinologists to learn from them?

Kola and Landis (2004) analysed the reasons why compounds failed during development. Their study covered compounds being developed by 10 large pharmaceutical companies in the period of 1991-2000. The overall success rate from phase I clinical trials to approval was $11 \%$. The main reasons for compounds being dropped were lack of efficacy ( $30 \%$ of failures), toxicity concerns $(\sim 30 \%)$, and commercial issues ( $20 \%)$. A more recent analysis of failures in phase II and III clinical trials showed that $56 \%$ failed because of lack of efficacy, $28 \%$ because of safety issues, and $12 \%$ for strategic or commercial reasons (Arrowsmith and Miller, 2013). A recent and more comprehensive survey of success rates during development covered over 4000 compounds from 835 companies between 2003 and 2011 (Hay et al., 2014). The overall success rate in going from phase I trials to gaining FDA approval was $10.4 \%$, with lack of efficacy remaining the main cause of failures. Clearly, there are still major problems along the path from discovery to market.

The reasons for the high attrition rates have been analysed and debated (e.g. Pammolli et al., 2011; Swinney and Anthony, 2011; Allison, 2012; Morgan et al., 2012; Scannell et al., 2012; SamsDodd, 2013; Cook et al., 2014; Eder et al., 2014). These follow on from the suggestions made earlier (Kola and Landis, 2004) of ways to reduce attrition: early validation that the proposed therapeutic target does play a critical role in the pathophysiology of the disease; using appropriate animal models in preclinical studies; avoiding compounds that have mechanism-based toxicity; using biomarkers in early clinical trials to confirm that appropriate dosing has been achieved in order to hit the compound's molecular target; improved design of proof-of-concept clinical trials; and better alignment of R\&D with market and competitor analyses.

While design of clinical trials can be improved (Allison, 2012), it seems that there needs to be a critical appraisal of the drug discovery and candidate selection process. Given that many compounds are failing through lack of efficacy in the clinic, the links between drug discovery screening and the actual disease being

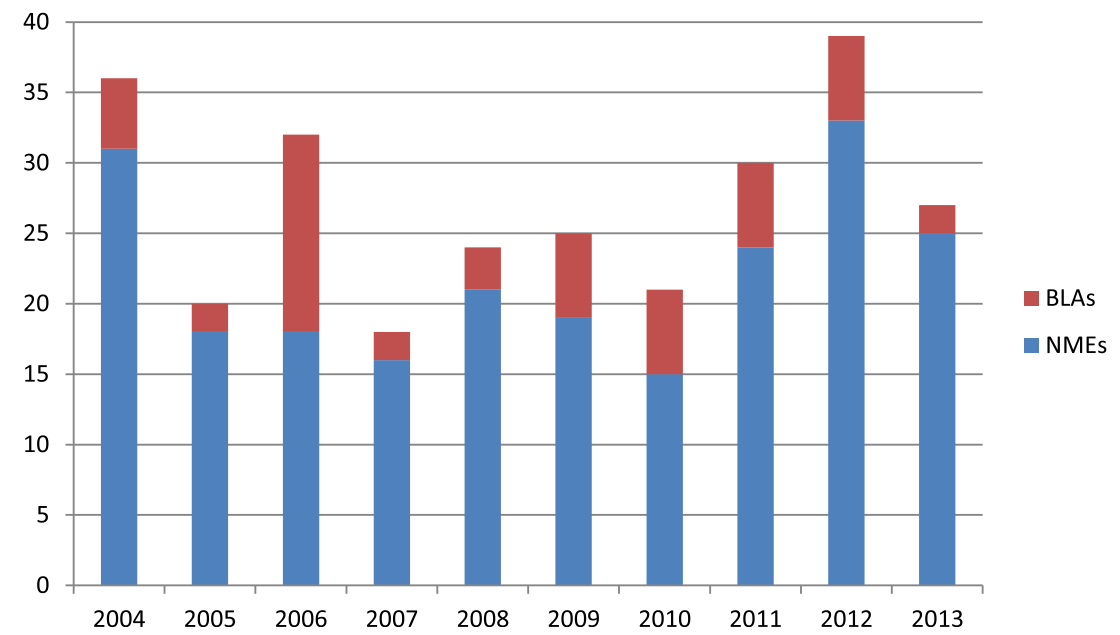

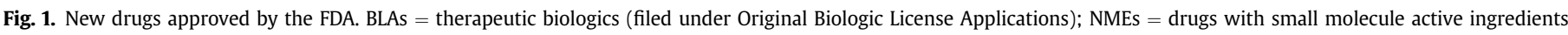
(New Molecular Entities). 
targeted must be weak. With the rapid adoption of the techniques of high-throughput screening, much of drug discovery is based on selecting single molecular targets as the basis for the screening assay. Despite advances in genomics and other modern techniques, it is still difficult to be sure that modulating a single molecular target will affect the course of the disease. A bioassay based on a functional or systems approach may be more likely to reflect the pathophysiology of the disease, but such approaches are less suitable for screening large numbers of compounds.

An analysis of the 75 novel ('first-in-class') drugs approved by the FDA between 1999 and 2008 emphasised the importance of using functional (or 'phenotypic') assays (Swinney and Anthony, 2011). Twenty-eight of the 50 small-molecule NMEs came from phenotypic screens, while 17 were from target-based assays and five were modifications of known natural products. A further 25 approved compounds were biologics or large-molecule NMEs: these can be taken as originating through target-based screening because they were created to modulate a known molecular activity. This analysis of first-in-class drugs approved by the FDA was extended to 2013 (Eder et al., 2014). A larger proportion of new drugs originated from target-based screening, but 30\% still came from systems-based assays.

It is further argued that the pharmaceutical industry has shifted from a focus on the patient and disease to one fixed on the process of drug discovery linked to using molecular targets in highthroughput assays (Sams-Dodd, 2013). This may be compounded by a desire to maintain a particular rate of progression of compounds through different stages of drug development (Cook et al., 2014). Consequently, the design of the drug discovery platform must match the disease in question, and particularly the selection of molecular targets becomes the critical step. However, this is often based on incomplete or imperfect knowledge of the disease. Target-based drug discovery also rests largely on the assumption that modulating a single molecule will influence the disease, but this is rarely the case in practice (Hopkins et al., 2006; Scannell et al., 2012). The high rate of clinical failures implies that targets are not sufficiently validated or that the intermediate step of functional testing in an animal model of the disease relies on nonpredictive surrogates for the human disease (Morgan et al., 2012; Sams-Dodd, 2013; Cook et al., 2014).

Going beyond these somewhat technical considerations, Scannell et al. (2012) discuss other hurdles blocking the path to drug approval. They argue that the on-going fall in productivity of drug development (as measured by the number of drugs approved per R\&D expenditure) is unlikely to be completely stemmed simply by improvements in technology. Two additional issues are highlighted. The first is termed the 'better than the Beatles' problem, which is that new drugs in many therapeutic areas have to achieve a very high standard for acceptance because they have to compete with older agents that are efficacious, well-understood by prescribers and likely to be much cheaper (because they may be offpatent). Scannell et al. (2012) also point out that the regulatory hurdles for drug approvals are consistently getting higher, making it more and more difficult for successful development of new compounds. With society's expectations that new medicines should be completely safe, this problem is unlikely to diminish.

\section{Lessons for toxinologists?}

Given that specialist biotechnology and pharmaceutical companies struggle to undertake successful drug discovery and development, it is hardly surprising that academic toxinologists have difficulties. However, by considering carefully the evidence from the successes and failures of others, toxinologists may leave behind their naïve optimism for their lab-based discoveries and apply their undoubted skills and insights more productively.

\subsection{Starting with the toxin}

Given that many new toxins are found because of their interactions with specific proteins, particularly enzymes, ion channels or receptors, there is a natural tendency for toxin-based drug discovery to be created around the expectation (or hope?) that the toxin's target protein is critical for the expression of a particular disease. Before proceeding too far down the path to establishing a drug development project, great care should be given to assessing the evidence for the clinical relevance of the target. It also should be remembered that the putative target is likely to be expressed at several sites in the body. Hence, there is always the possibility that the toxin will have unexpected and unwanted effects in vivo.

As mentioned earlier, few diseases are caused by dysfunction of single genes. Therefore, a highly specific toxin may not have much impact on the overall pathophysiological process. However, the 'translatability' of a putative target can be assessed (Wehling, 2009) and there are some promising examples in recent toxin studies. Mutations in the human gene SNC9A that encodes a sub-unit of the $\mathrm{Na}_{\mathrm{v}} 1.7$ sodium ion channel is associated with individuals' perception of pain. A screening programme based around testing venoms on currents through $\mathrm{Na}_{\mathrm{v}} 1.7$ sodium ion channels uncovered a potent and highly selective blocking peptide (Ssm6a) from a centipede (Yang et al., 2013). This peptide was active in three mice models of pain, and may, therefore, be a potential drug development prototype.

\subsection{Starting from the disease}

Another approach is to work backwards from a disease to create an appropriate screening programme. In this case, care should be taken to make sure that the disease represents significant unmet therapeutic needs and the nature of the competitive landscape should be defined. Scannell et al. (2012) postulate that a focus on cancer or on neglected diseases may be fruitful because the "better than the Beatles' problem will be less when there are few existing treatments to contend with and because the attitudes of the regulatory authorities may be more encouraging towards new developments in these areas. Others have suggested that small-scale clinical trials in rare diseases may be a route to rapid approval and can lead to broader uses of the drugs for more common diseases (Fishman and Porter, 2005; Kocher and Roberts, 2014).

In addition, it may be more productive to base the screening campaign on phenotypic assays rather than on single molecular targets. With venoms and toxins, there are unlikely to be thousands of samples to be tested so high-throughput approaches should not be essential. The validity of phenotypic assays still needs to be rigorously assessed before being implemented (Horrobin, 2003; Wehling, 2009; Zheng et al., 2013).

The original phenotypic screen for effect of venoms is the envenomed victim: close observation of the signs and symptoms during envenoming could reveal some unusual pharmacological activity caused by a component of the venom. Knowledge that envenoming by certain snakes was accompanied by severe persistent pain led to the finding of a dimeric complex (MiTx) from the venom of the Texas coral snake Micrurus tener tener that activated some ASIC channels in vitro and induced pain-like behaviour in mice (Bohlen et al., 2011). Further screening of venoms resulted in finding potent and highly selective blockers of relevant ASIC channels (Diochot et al., 2012). In turn, these might be drug development leads. 
Previously, observations of envenomed experimental animals indicated the presence of novel toxins. The unusual appearance of mice following injections with green mamba (D. angusticeps) venom prompted further pharmacological investigations that found the potassium ion channel blocking dendrotoxins and the inhibitor of acetylcholinesterase activity, fasciculin (Harvey et al., 1984). Comparison of effects of Conus venoms in mice following intravenous or intracerebroventricular injection revealed different behavioural phenotypes that guided the isolation of novel conopeptides (for example, Olivera et al., 1985).

For ethical, practical and scientific reasons, random screening of venoms in mice would no longer be considered. However, it may be possible to screen for novel activities using model organisms (such as nematodes (Caenorhabditis elegans) and zebrafish (Danio rerio) that have found some use in other drug discovery projects (Giacomotto and Ségalat, 2010; Delvecchio et al., 2011; Asnani and Peterson, 2014; Bruni et al., 2014). Various zebrafish lines are available to allow effects on specific developmental and physiological process to be readily studied in transparent embryos in 96well plates, and model systems for a wide range of human tumours are being developed in zebrafish (Mimeault and Batra, 2013). With the on-going interest in venom components as potential anticancer agents the latter might be particularly attractive.

Although zebrafish embryos have been increasingly used in toxicological and pharmacological studies (e.g., to screen for antiepileptic compounds from medicinal plants, Challal et al., in press), their use is too new to have provided clear evidence of their ability to predict efficacy in humans. Additional experimental models are still going to be required to aid the reliable translation of drug candidates from the lab to the clinic. In the oncology area, for example, these models might be studies in patient-derived tumours in immunocompromised mice or genetically engineered mouse models that come close to resembling human tumours (see the review by Cook et al., 2012).

Cell-based systems are also used for phenotypic screening. Effects can be changes in cell morphology, rate of cell multiplication, or signalling behaviour. For example, many studies with venoms and toxins have used cancer cell lines, although these may be poor predictors of effectiveness on tumours in patients. Primary cultures derived directly from patients may be more reliable (Cree et al., 2010). Recent papers have highlighted the use of cultured neurones to detect effects of various venoms and toxins on ion channels (Yang et al., 2013; Imperial et al., 2014).

\subsection{Find a partner with deep pockets}

Although some universities may be able to afford to pay for drug development programmes (Christini, 2012), academics typically need external funding in order to see their toxin enter the development process. Such funding can come from investment into a start-up company or through collaboration with an existing biotechnology company (direct links with major pharmaceutical companies on toxin-based drug discovery and development seem to be rare). In all cases, patience and deep pockets are necessary. In the USA, the average time from the formation of a biotechnology company to its first FDA approval was 11.3 years (Kinch, 2014a). Hence, such companies need substantial funds from investors over a protracted period. The lack of success of companies founded in Europe and Australia to develop toxin-based drugs might, in part, be because of difficulties in obtaining the necessary investment. Even in USA, there are concerns for the health of the early-stage drug discovery endeavour: fewer biotechnology companies are being created than previously (Kinch et al., 2014) and there are fewer venture capital investments going into companies with products that are only in preclinical development (Christini, 2012).
The investment focus has shifted to companies with products in at least phase II clinical trials. Similarly, pharmaceutical companies are not tending to partner as often as before with biotechnology companies at the preclinical stage.

\subsection{Reasons to be cheerful}

Despite all the caveats expressed above, it should be remembered that academic researchers have made substantial contributions to successful drug developments. An analysis of the 144 FDAapproved NMEs from 1998 to 2003 showed that 26 were associated with inventions made in a university or public research organisation; in the same period, six of the 26 approved new biological entities were based on university inventions (Kneller, 2005). When the analysis was extended to 2007, it covered 252 new drugs, of which $24 \%$ originated from university patents (Kneller, 2010).

With appropriate selection of disease target, toxin and partner, further successes will emerge from explorations of the drug-like potential of toxins.

\section{Ethical statement}

This submission is a review article. No ethical issues are involved.

\section{Conflict of interest}

I confirm that I have no conflicts of interest in relation to this submission.

\section{References}

Abrams, S.B., Hallett, M., 2013. Clinical utility of different botulinum neurotoxin preparations. Toxicon 67, 81-86.

Adams, D.J., Berecki, G., 2013. Mechanisms of conotoxin inhibition of N-type (Cav2.2) calcium channels. Biochim. Biophys. Acta 1828, 1619-1628.

Allison, M., 2012. Reinventing clinical trials. Nat. Biotech. 30, 41-49.

Arneric, S.P., Holladay, M., Williams, M., 2007. Neuronal nicotinic receptors: a perspective on two decades of drug discovery research. Biochem. Pharmacol. 74, 1092-1101.

Arrowsmith, J., Miller, P., 2013. Trial watch: phase II and phase III attrition rates 2011-2012. Nat. Rev. Drug Discov. 12, 569.

Asnani, A., Peterson, R.T., 2014. The zebrafish as a tool to identify novel therapies for human cardiovascular disease. Dis. Model Mech. 7, 763-767.

Baron, A., Diochot, S., Salinas, M., Deval, E., Noël, J., Lingueglia, E., 2013. Venom toxins in the exploration of molecular, physiological and pathophysiological functions of acid-sensing ion channels. Toxicon 75, 187-204.

Beeton, C., Pennington, M.W., Norton, R.S., 2011. Analogs of the sea anemone potassium channel blocker ShK for the treatment of autoimmune diseases. Inflamm. Allergy Drug Targets 10, 313-321.

Bohlen, C.J., Chesler, A.T., Sharif-Naeini, R., Medzihradszky, K.F., Zhou, S., King, D. Sánchez, E.E., Burlingame, A.L., Basbaum, A.I., Julius, D., 2011. A heteromeric Texas coral snake toxin targets acid-sensing ion channels to produce pain. Nature 479, 410-414.

Bowman, W.C., 2006. Neuromuscular block. Br. J. Pharmacol. 147 (Suppl. 1), S277-S286.

Bruni, G., Lakhani, P., Kokel, D., 2014. Discovering novel neuroactive drugs through high-throughput behavior-based chemical screening in the zebrafish. Front. Pharmacol. 5, 153.

Camargo, A.C., Ianzer, D., Guerreiro, J.R., Serrano, S.M., 2012. Bradykinin-potentiating peptides: beyond captopril. Toxicon 59, 516-523.

Challal, S., Buenafe, O.E., Queiroz, E., Maljevic, S., Marcourt, L., Bock, M., Kloeti, W., Dayrit, F., Harvey, A.L., Lerche, H., Esguerra, C., de Witte, P., Wolfender, J.-L., Crawford, A., 2014. Zebrafish-bioassay guided microfractionation identifies anticonvulsant steroid glycosides from the Philippine medicinal plant Solanum torvum. ACS Chem. Neurosci. 5, 993-1004.

Chi, V., Pennington, M.W., Norton, R.S., Tarcha, E.J., Londono, L.M., Sims-Fahey, B., Upadhyay, S.K., Lakey, J.T., Iadonato, S., Wulff, H., Beeton, C., Chandy, K.G., 2012. Development of a sea anemone toxin as an immunomodulator for therapy of autoimmune diseases. Toxicon 59, 529-546.

Christini, A., 2012. Why universities should step up in venture investing. Nat. Biotech. 30, 933-936.

Commonwealth of Australia Gazette, 2010. ASIC Gazette - Company Deregistrations. No. A036/10, Friday, 23 April 2010. 
Cook, D., Brown, D., Alexander, R., March, R., Morgan, P., Satterthwaite, G., Pangalos, M.N., 2014. Lessons learned from the fate of AstraZeneca's drug pipeline: a five-dimensional framework. Nat. Rev. Drug Discov. 13, 419-431.

Cook, N., Jodrell, D.I., Tuveson, D.A., 2012. Predictive in vivo animal models and translation to clinical trials. Drug Discov. Today 17, 253-260.

Cree, I.A., Glaysher, S., Harvey, A.L., 2010. Efficacy of anti-cancer agents in cell lines versus human primary tumour tissue. Curr. Opin. Pharmacol. 10, $375-379$.

Cushman, D.W., Cheung, H.S., Sabo, E.F., Ondetti, M.A., 1977. Design of potent competitive inhibitors of angiotensin-converting enzyme. Carboxyalkanoyl and mercaptoalkanoyl amino acids. Biochemistry 16, 5484-5491.

Daly, J.W., 1982. Alkaloids of neotropical poison frogs (Dendrobatidae). Fortschr: Chem. Org Naturst, 41, 205-340.

Delvecchio, C., Tiefenbach, J., Krause, H.M., 2011. The zebrafish: a powerful platform for in vivo, HTS drug discovery. Assay Drug Dev. Technol. 9, 354-361.

Deshane, J., Garner, C.C., Sontheimer, H., 2003. Chlorotoxin inhibits glioma cell invasion via matrix metalloproteinase-2. J. Biol. Chem. 278, 4135-4144.

Diochot, S., Baron, A., Salinas, M., Douguet, D., Scarzello, S., Dabert-Gay, A.S. Debayle, D., Friend, V., Alloui, A., Lazdunski, M., Lingueglia, E., 2012. Black mamba venom peptides target acid-sensing ion channels to abolish pain. Nature 490, 552-555.

Dolly, J.O., Wang, J., Zurawski, T.H., Meng, J., 2011. Novel therapeutics based on recombinant botulinum neurotoxins to normalize the release of transmitters and pain mediators. FEBS J. 278, 4454-4466.

Earl, S.T., Masci, P.P., de Jersey, J., Lavin, M.F., Dixon, J., 2012. Drug development from Australian elapid snake venoms and the Venomics pipeline of candidates for haemostasis: Textilinin-1 (Q8008), Haempatch ${ }^{\mathrm{TM}}$ (Q8009) and CoVase ${ }^{\mathrm{TM}}$ (V0801). Toxicon 59, 456-463.

Eder, J., Sedrani, R., Wiesmann, C., 2014. The discovery of first-in-class drugs: origins and evolution. Nat. Rev. Drug Discov. 13, 577-587.

Essack, M., Bajic, V.B., Archer, J.A., 2012. Conotoxins that confer therapeutic possibilities. Mar. Drugs 10, 1244-1265.

Fishman, M.C., Porter, J.A., 2005. Pharmaceuticals: a new grammar for drug discovery. Nature 437, 491-493.

Fox, J.W., Serrano, S.M., 2007. Approaching the golden age of natural product pharmaceuticals from venom libraries: an overview of toxins and toxinderivatives currently involved in therapeutic or diagnostic applications. Curr Pharm. Des. 13, 2927-2934.

Giacomotto, J., Ségalat, L., 2010. High-throughput screening and small anima models, where are we? Br. J. Pharmacol. 160, 204-216.

Giorgi, R., Bernardi, M.M., Cury, Y., 1993. Analgesic effect evoked by low molecula weight substances extracted from Crotalus durissus terrificus venom. Toxicon 31 1257-1265.

Glogau, R., Blitzer, A., Brandt, F., Kane, M., Monheit, G.D., Waugh, J.M., 2012. Results of a randomized, double-blind, placebo-controlled study to evaluate the efficacy and safety of a botulinum toxin type A topical gel for the treatment of moderate-to-severe lateral canthal lines. J. Drugs Dermatol. 11, 38-45.

Groeneveld, G.J., 2013. Examples of Go and No-go Decisions After Rigorous Early Phase Drug Evaluation. https://isctm.org/public_access/Oct_2013/ presentations/2013_Autumn_Groeneveld.pdf.

Gutierrez, V.P., Zambelli, V.O., Picolo, G., Chacur, M. Sampaio, S.C., Brigatte, P. Konno, K., Cury, Y., 2012. The peripheral L-arginine-nitric oxide-cyclic GMP pathway and ATP-sensitive $\mathrm{K}^{+}$channels are involved in the antinociceptive ef fect of crotalphine on neuropathic pain in rats. Behav. Pharmacol. 23, 14-24.

Hagen, N.A., Fisher, K.M., Lapointe, B., du Souich, P., Chary, S., Moulin, D., Sellers, E Ngoc, A.H., Canadian Tetrodotoxin Study Group, 2007. An open-label, multidose efficacy and safety study of intramuscular tetrodotoxin in patients with severe cancer-related pain. J. Pain Symptom Manage 34, 171-182.

Hagen, N.A., du Souich, P., Lapointe, B., Ong-Lam, M., Dubuc, B., Walde, D., Love, R., Ngoc AH, Canadian Tetrodotoxin Study Group, 2008. Tetrodotoxin for moderate to severe cancer pain: a randomized, double blind, parallel design multicenter study. J. Pain Symptom Manage 35, 420-429.

Hagen, N.A., Lapointe, B., Ong-Lam, M., Dubuc, B., Walde, D., Gagnon, B., Love, R. Goel, R., Hawley, P., Ngoc, A.H., du Souich, P., 2011. A multicentre open-labe safety and efficacy study of tetrodotoxin for cancer pain. Curr. Oncol. 18 e109-116.

Harvey, A.L., 1992. From venom to toxin to drug? Proc. R. Soc. Edinb. 99B, 55-65.

Harvey, A.L., Anderson, A.J., Mbugua, P.M., Karlsson, E., 1984. Toxins from mamba venoms that facilitate neuromuscular transmission. J. Toxicol. Toxin Rev. 3 91-137.

Hashemzadeh, M., Furukawa, M., Goldsberry, S., Movahed, M.R., 2008. Chemical structures and mode of action of intravenous glycoprotein IIb/IIIa receptor blockers: a review. Exp. Clin. Cardiol. 13, 192-197.

Hay, M., Thomas, D.W., Craighead, J.L., Economides, C., Rosenthal, J., 2014. Clinica development success rates for investigational drugs. Nat. Biotechnol. 32, 40-51.

Hopkins, A.L., Mason, J.S., Overington, J.P., 2006. Can we rationally design promiscuous drugs? Curr. Opin. Struct. Biol. 16, 127-136.

Horrobin, D.F., 2003. Modern biomedical research: an internally self-consistent universe with little contact with medical reality? Nat. Rev. Drug Discov. 2 $151-154$.

Imperial, J.S., Cabang, A.B., Song, J., Raghuraman, S., Gajewiak, J., Watkins, M. Showers-Corneli, P., Fedosov, A., Concepcion, G.P., Terlau, H., Teichert, R.W. Olivera, B.M. 2014. A family of excitatory peptide toxins from venomous crassispirine snails: using Constellation Pharmacology to assess bioactivity. Toxicon $89,45-54$
Kinch, M.S., 2014a Apr 18. The rise (and decline?) of biotechnology. Drug Discov. Today. http://dx.doi.org/10.1016/j.drudis.2014.04.006 pii: S1359-6446(14) 00131-7.

Kinch, M.S., 2014b Sep 16. An overview of FDA-approved biologics medicines. Drug Discov. Today. http://dx.doi.org/10.1016/j.drudis.2014.09.003 pii: S1359-6446(14)00350-X.

Kinch, M.S., Haynesworth, A., Kinch, S.L., Hoyer, D., 2014. An overview of FDAapproved new molecular entities: 1827-2013. Drug Discov. Today 19, 1033-1039.

King, G.F., 2011. Venoms as a platform for human drugs: translating toxins into therapeutics. Expert Opin. Biol. Ther. 11, 1469-1484.

Klint, J.K., Senff, S., Rupasinghe, D.B., Er, S.Y., Herzig, V., Nicholson, G.M., King, G.F., 2012. Spider-venom peptides that target voltage-gated sodium channels: pharmacological tools and potential therapeutic leads. Toxicon 60, 478-491.

Kneller, R., 2005. The origins of new drugs. Nat. Biotechnol. 23, 529-530.

Kneller, R., 2010. The importance of new companies for drug discovery: origins of a decade of new drugs. Nat. Rev. Drug Discov. 9, 867-882.

Kocher, R., Roberts, B., 2014. The calculus of cures. N. Engl. J. Med. 370, 1473-1475.

Koh, C.Y., Kini, R.M., 2012. From snake venom toxins to therapeutics-cardiovascular examples. Toxicon 59, 497-506.

Kola, I., Landis, J., 2004. Can the pharmaceutical industry reduce attrition rates? Nat. Rev. Drug Discov. 3, 711-715.

Kolosov, A., Goodchild, C.S., Cooke, I., 2010. CNSB004 (Leconotide) causes antihyperalgesia without side effects when given intravenously: a comparison with ziconotide in a rat model of diabetic neuropathic pain. Pain Med. 11, $262-273$.

Konno, K., Picolo, G., Gutierrez, V.P., Brigatte, P., Zambelli, V.O., Camargo, A.C., Cury, Y., 2008. Crotalphine, a novel potent analgesic peptide from the venom of the South American rattlesnake Crotalus durissus terrificus. Peptides 29, 1293-1304.

Kornalík, F., 1991. The Influence of Snake Venom Enzymes on Blood Coagulation. In: Harvey, A.L. (Ed.), 'Snake Toxins'. Pergamon Press, Oxford, pp. 323-383.

Lewis, R.J., 2012. Discovery and development of the $\chi$-conopeptide class of analgesic peptides. Toxicon 59, 524-528.

Lewis, R.J., Garcia, M.L., 2003. Therapeutic potential of venom peptides. Nat. Rev. Drug Discov. 2, 790-802.

Lipps, B.V., 2004. Australian Taipan snake venom to synthetic Oxynor for wound healing. Wound Repair Regen. 12, A3.

Machado, F.C., Zambelli, V.O., Fernandes, A.C., Heimann, A.S., Cury, Y., Picolo, G., 2014. Peripheral interactions between cannabinoid and opioid systems contribute to the antinociceptive effect of crotalphine. Br. J. Pharmacol. 171, 961-972.

Matak, I., Lacković, Z., 2014. Botulinum toxin A, brain and pain. Prog. Neurobiol. 119-120, 39-59.

McKie, P.M., Sangaralingham, S.J., Burnett Jr., J.C., 2010. CD-NP: an innovative designer natriuretic peptide activator of particulate guanylyl cyclase receptors for cardiorenal disease. Curr. Heart Fail Rep. 7, 93-99.

Mimeault, M., Batra, S.K., 2013. Emergence of zebrafish models in oncology for validating novel anticancer drug targets and nanomaterials. Drug Discov. Today $18,128-140$.

Minea, R., Helchowski, C., Rubino, B., Brodmann, K., Swenson, S., Markland Jr., F. 2012. Development of a chimeric recombinant disintegrin as a cost-effective anti-cancer agent with promising translational potential. Toxicon 59, 472-486.

Morgan, P., Van Der Graaf, P.H., Arrowsmith, J., Feltner, D.E., Drummond, K.S., Wegner, C.D., Street, S.D., 2012. Can the flow of medicines be improved? Fundamental pharmacokinetic and pharmacological principles toward improving Phase II survival. Drug Discov. Today 17, 419-424.

Mortari, M.R., Cunha, A.O.S., 2013. New perspectives in drug discovery using neuroactive molecules from the venom of arthropods, an integrated view of the molecular recognition and toxinology. In: Radis-Baptista, G. (Ed.), Analytical Procedures to Biomedical Applications. InTech. ISBN: 978-953-51-1151-1, DOI: $10.5772 / 52382$.

Newman, D.J., Cragg, G.M., 2012. Natural products as sources of new drugs over the 30 years from 1981 to 2010. J. Nat. Prod. 75, 311-335.

Olivera, B.M., McIntosh, J.M., Clark, C., Middlemas, D., Gray, W.R., Cruz, L.J., 1985. A sleep-inducing peptide from Conus geographus venom. Toxicon 23, 277-282.

Opie, L.H., Kowolik, H., 1995. The discovery of captopril: from large animals to small molecules. Cardiovasc. Res. 30, 18-25.

Pammolli, F., Magazzini, L., Riccaboni, M., 2011. The productivity crisis in pharmaceutical R\&D. Nat. Rev. Drug Discov. 10, 428-438.

Philippe, G., Angenot, L., 2005. Recent developments in the field of arrow and dart poisons. J. Ethnopharmacol. 100, 85-91.

PhRMA, 2013. Biologics Research Promises to Bolster the Future of Medicine. Report. http://www.phrma.org/sites/default/files/pdf/biologics2013.pdf.

Pope, J.E., Deer, T.R., 2013. Ziconotide: a clinical update and pharmacologic review. Expert Opin. Pharmacother. 14, 9957-9966.

Pu, X.C., Wong, P.T., Gopalakrishnakone, P., 1995. A novel analgesic toxin (hannalgesin) from the venom of king cobra (Ophiophagus hannah). Toxicon 33, $1425-1431$.

Sams-Dodd, F., 2013. Is poor research the cause of the declining productivity of the pharmaceutical industry? An industry in need of a paradigm shift. Drug Discov. Today 18, 211-217.

Scannell, J.W., Blanckley, A., Boldon, H., Warrington, B., 2012. Diagnosing the decline in pharmaceutical R\&D efficiency. Nat. Rev. Drug Discov. 11, 191-200. 
Shaw, C., October 2009. Venom-based medicines. Advancing drug discovery with reptile and amphibian venom peptides. Biochem. Evol. 34-37. www. biochemist.org/bio/03105/0034/031050034.pdf.

Smith, C.G., Vane, J.R., 2003. The discovery of captopril. FASEB J. 17, 788-789.

Stenlake, J.B., Waigh, R.D., Urwin, J., Dewar, G.H., Coker, G.G., 1983. Atracurium: conception and inception. Br. J. Anaesth. 55 (Suppl. 1), 3S-10S.

Stöcklin, R., 2012. XEP-018: a new myorelaxant peptide lead compound from the venom of the cone snail Conus consors. In: Proc. 7th Annual Peptide Therapeutics Symposium, p. 32

Swinney, D.C., Anthony, J., 2011. How were new medicines discovered? Nat. Rev. Drug Discov. 10, 507-519.

Takacs, Z., Nathan, S., 2014. Animal venoms in medicine. In: Wexler, P. (Ed.), Encyclopedia of Toxicology, third ed, vol. 1. Academic Press, pp. 252-259.

Twede, V.D., Miljanich, G., Olivera, B.M., Bulaj, G., 2009. Neuroprotective and cardioprotective conopeptides: an emerging class of drug leads. Curr. Opin. Drug Discov. Dev. 12, 231-239.

US Patent, 2003. Therapeutic Molecules Derived from Snake Venom. Gopalakrishnakone P, Pu XC, Wong PT-H, Gwee MCE, Kini RM. US 6,613,745.

US Patent, 2010. Modified Elapid Venoms as Stimulators of the Immune Reaction. Reid PF, Raymond LN. US 7,758,894.

US Patent Application, 2009. Analog Compounds of Analgesic Peptides Derived from the Venom of Crotalus durissus terrificus Snakes, Their Uses, Compositions,
Methods of Preparation and Purification. Cury Y, Picolo G, Konno K, Giorgi R, Brigatte P, Gutierrez V, Camargo A. Number 20090203618.

US Patent Application, 2012. Analgesic Composition for Transbuccal Administration. Lazdunski M. Number 2012/0183580.

Vetter, I., Lewis, R.J., 2012. Therapeutic potential of cone snail venom peptides (conopeptides). Curr. Top. Med. Chem. 12, 1546-1552.

Vink, S., Jin, A.H., Poth, K.J., Head, G.A., Alewood, P.F., 2012. Natriuretic peptide drug leads from snake venom. Toxicon 59, 434-445.

Wehling, M., 2009. Assessing the translatability of drug projects: what needs to be scored to predict success? Nat. Rev. Drug Discov. 8, 541-546.

Wu, X.S., Jian, X.C., Yin, B., He, Z.J., 2010. Development of the research on the application of chlorotoxin in imaging diagnostics and targeted therapies for tumors. Chin. J. Cancer 29, 626-630.

Yang, S., Xiao, Y., Kang, D., Liu, J., Li, Y., Undheim, E.A., Klint, J.K., Rong, M., Lai, R. King, G.F., 2013. Discovery of a selective NaV1.7 inhibitor from centipede venom with analgesic efficacy exceeding morphine in rodent pain models. Proc. Natl. Acad. Sci. U. S. A. 110, 17534-17539.

Zambelli, V.O., Fernandes, A.C., Gutierrez, V.P., Ferreira, J.C., Parada, C.A., MochlyRosen, D., Cury, Y., 2014. Peripheral sensitization increases opioid receptor expression and activation by crotalphine in rats. PLoS One 9, e90576.

Zheng, W., Thorne, N., McKew, J.C., 2013. Phenotypic screens as a renewed approach for drug discovery. Drug Discov. Today 18, 1067-1073. 